\title{
Asamblea Constituyente. La alternativa democrática para Chile Sergio Grez y Foro por la Asamblea Constituyente
}

\author{
Editorial América en Movimiento, Santiago, Chile, \\ 2015, 109 págs. \\ Paula Vidal Molina \\ Universidad de Chile, Santiago, Chile. \\ Email: pvidal71@yahoo.com
}

Sergio Grez y el Foro por la Asamblea Constituyente han puesto a disposición de la ciudadanía una obra que permite comprender la necesidad, deber y desafíos que posee cada uno de nosotros en la construcción o refundación de la sociedad chilena. Este libro es un llamado a criticar el estado actual de las cosas, a oponerse a la violencia de la imposición de un modelo de sociedad que agotó sus posibilidades de ofrecer bienestar y desarrollo a la ciudadanía, nos invita -como ciudadanos- a aparecer en lo público y a tomar las "riendas" mediante mecanismos que se oponen a la violencia, a la negación de los de los sectores subalternos y al autoritarismo.

Este libro se distancia de lo que Sergio Grezha brindado al público, con destacadas obras como La "cuestión social" en Chile. Ideas y debates precursores (1804-1903) (Santiago, DIBAM, 1995); De la "regeneración del pueblo" a la huelga general. Génesis y evolución histórica del movimiento popular en Chile (1810-1890) (Santiago, DIBAM, 1997); Los anarquistas y el movimiento obrero. La alborada de "la Idea" en Chile (1893-1915) (Santiago, Lom Ediciones, 2007); Magno Espinoza. La pasión por el comunismo libertario (Santiago, Editorial de la Universidad de Santiago de Chile, 2011); ¿Autonomía o escudo protector? El movimiento obrero y popular y los mecanismos de conciliación y arbitraje (Chile, 1900-1924) (Saarbrücken, Alemania, Editorial Académica Española, 2011); Historia del comunismo en Chile. La era de Recabarren (1912-1924) (Santiago, Lom Ediciones, 2011); El Partido Democrático de Chile. Auge y ocaso de una organización política popular (1887-1927) (Santiago, Lom Ediciones, 2016, en prensa). Todas ellas volcadas al riguroso análisis historiográfico del Chile de fines del siglo XIX y mediados del XX, centrada en el estudio del movimiento popular y de la "cuestión social” en Chile.

A diferencia de los anteriores, en este libro Sergio va y viene entre pasado, presente y futuro,donde uno de los posibles hilos conductores esdemostrar la sistemática negación que ha sufrido la ciudadanía chilena, 
de elaborar una Constitución democrática,y la potencialidad de construirla mediante una “Asamblea Constituyente libre, soberana, democrática y representativa” (p.9) donde se manifieste la capacidad de reflexión, diálogo y autodeterminación que posee el pueblo chileno para darse sus propias normas y leyes. Por lo tanto, este libro cristaliza, no solo, la preocupación de Sergio con los problemas sociopolíticos que han estructurado la historia chilena en los últimos siglos, sino también su opción de comprender la actividad intelectual y académica, en relación con el movimiento social, la ciudadanía y sus demandas,ayudando con ello -en su labor de intelectual orgánico de las clases subalternas (como diría Gramsci)- a diseñar un nuevo tipo de sociedad chilena.

La estructura del libro, que contempla 3 partes, con 7 capítulos y un epílogo, es una totalidad explicativa de las tensiones y desafíos que tenemos en el Chile contemporáneo para darnos una nueva Constitución verdaderamente democrática. Sin embargo, también cada una de las partesposee su propia riqueza, y entrega las posibilidades de una lectura plural según los objetivos del lector. En el libro, se encuentranaproximaciones históricas, conceptuales y herramientas procedimentales para poder llevar a cabo la tarea de construir una nueva base socio-histórica, a través de un mecanismo soberano, libre, democrático, y representativo. El texto posee un carácter pedagógico, pues con un lenguaje simple, e infografías sintetizadoras de cada parte, aproxima a todo lector en: 1.- un análisis histórico del proceso constitucional chileno desde el siglo XIX a la actualidad, caracterizado por la ausencia de un poder constituyente democrático, 2.- las condiciones históricas que permitieron y legitimaron la constitución de 1980 en Chile hasta hoy, 3.- las razones políticas, sociales, económicas que obligan a rechazar la actual constitución, 4.- los fundamentos y mecanismos concretos que permiten asegurar que el cambio constitucional sea democrático y popular, por lo tanto, el rechazo a que cualquier mecanismo sea utilizado para este cambio.

Los autores sostienen que la vía -sustantivamente-democrática y participativa es la opción que se debiera defender y que nunca ha sido materializada en la república de Chile. La historia da cuenta que, tanto los “ensayos constitucionales realizados durante los años de la lucha por la Independencia, (...) la emancipación política de Chile fue un acto eminentemente aristocrático” (p. 16), como los intentos de los sectores populares de “hacer oír su voz en el debate constitucional” (p. 30) de 1925, a través de la “Asamblea Constituyente de Obreros e Intelectuales”, no fueron considerados por Alessandri, imponiendo un plebiscito (con apoyo militar). El sangriento y violento golpe de Estado en 1973, instala la Constitución de 1980, elaborada por una comisión designada por los militares y aprobada por un plebiscito (sin garantías de transparencia), pero que desde los años noventa será legitimada por los gobiernos de la Concertación mediante las reformas constitucionales, "los gobiernos de la Concertación legitimaron, consolidaron y perfeccionaron pacíficamente la obra refundacional impuesta a sangre y fuego por la dictadura. Así como era imposible en 1973 que un modelo neoliberal fuera aceptado por la sociedad chilena, también le era 
imposible a la derecha en 1990 generar las condiciones para que dicho modelo fuese efectivamente legitimado y consolidado. Ese rol solo podía desempeñarlo una coalición gobernante-nominalmente-de centroizquierda. Ese fue, en definitiva, el rol histórico principal de la Concertación” (p.59).

Después de las movilizaciones estudiantiles del año 2011 a nivel nacional, la ciudadanía paulatina y crecientemente ha venido cuestionando las consecuencias sociales, económicas, políticas, ambientales y culturales nefastas para la sociedad -especialmente los sectores subalternos- que se derivan de la actual constitución, lo que generó que el segundo gobierno de Michelle Bachelet anunciara la apertura de un nuevo proceso constitucional.

Para los autores, una democracia representativa, participativa y social es un derecho que tenemos, el cual se expresa en tres sentidos: a) que permita una "auténtica y real representación de la soberanía popular", b) que permita una "auténtica y real participación de los ciudadanos en la gestión de todas las decisiones que los afectan" y c) que "promueva y garantice derechos políticos, económicos, sociales y culturales fundamentales” (p.64).Los autores revisan cada uno de estos aspectos en el actual sistema político chileno, ratificando - una vez más- la urgencia de un cambio constitucional que respete la construcción democrática en esos tres sentidos.

Hacen un llamado a que el poder constituyente de cada uno de los ciudadanos pueda ser ejercido y evitar que se imponga -una vez más- "una nueva institucionalidad desde arriba” (p.79). El camino procedimental -profundamente democrático- para construir la nueva constitución, sería la Asamblea Constituyente y la ratificación de esta constitución, mediante un plebiscito.

La Asamblea Constituyente se distingue de otros conceptos similares como el de la Asamblea Popular, y que el texto aclara en su epílogo, para evitar confusiones y esbozar sus determinaciones. La "Constituyente" expresa a todos los sectores y clases sociales del país, y se eligen sus representantes o delegados (que residan en Chile o el extranjero) mediante el sufragio universal y métodos representativos, por lo que contiene en su seno un terreno de "enfrentamiento de distintos proyectos de institucionalidad y sociedad futura” (p.102).

Hasta aquí, el libro refleja el momento histórico trascendental que vive el país, esto es -en el decir de Gramsci- el de la gran política, entendida como la fase en que la discusión y disputa es sobre cuestiones de fondo, como el proyecto de sociedad, la estructura y relaciones sociales que se desea tener. Al contrario, la pequeña política (a la que estamos acostumbrados por los diversos medios de información) discute cuestiones ornamentales que no critican la base y causas de la estructura social, pues las diversas posiciones están de acuerdo (por lo tanto la preocupación es sobre los cupos de legislativos, las votaciones electorales, la orientación de los programas sociales, etc.). El libro nos obliga a pensar y actuar en un 
registro de la gran política, que ha sido la construcción que ha venido realizando el movimiento político-social en el último tiempo.

Para finalizar, un elemento que quiero destacar de los múltiples que levanta este libro, es la interpelación que realiza a toda la población, a tomar posiciones como ciudadanos, pero también como académicos y profesionales de las ciencias sociales. Debido a queobliga a preguntarse sobre el tipo de sociedad, de Estado, de valores y principios que tenemos en la actualidad, al mismo tiempo y debido a ese mismo movimiento cuestionador, esbozamos el tipo de sociedad deseada, y en particular el rol y posición que le caben a las ciencias sociales en su construcción.

Nos parece natural que las ciencias sociales, y el mundo académico se abstenga de tomar posiciones vinculadas al movimiento político-social, o evite pronunciarse públicamente respecto de las demandas sociales de los sectores subalternos. Estos parecen estar ahí para ser estudiados, pero en ningún caso, para hacer propia sus demandas. El problema es que olvidamos que este distanciamiento, o la exigencia de neutralidad, responden a la marca que ha dejado (entre otros aspectos y fenómenos que escapan al proceso particular chileno), el orden político-institucional vigente, que transformó todo a su paso, incluidas las ciencias sociales y la academia.

En los años 60 hasta antes del golpe de Estado, fue natural comprender que las ciencias sociales no eran neutras y se anclaban a la historicidad de los procesos sociales, levantando críticas profundas a la estructura social que mantenía los privilegios de unos pocos, así, su cercanía al movimiento político-social era constitutiva del lugar que cumplían en la sociedad.

Me parece que este libro anula la imparcialidad como salida, nos enfrenta en nuestra calidad de ciudadanos(a académicos e investigadores), a tomar posición a favor del cambio constitucional, democrático y participativo, poniendo en su centro el respeto de los derechos sociales, económicos, políticos, culturales y ambientales para la sociedad en su conjunto, porque No da lo mismo el Chile que tenemos, donde las relaciones sociales están mediadas por el dinero, donde la mercantilización es el núcleo que otorga sentido a todas las esferas de la vida, donde el Estado se pone a disposición del mantenimiento de este tipo de relaciones, sin permitir la participación sustantiva ni la autodeterminación de los sujetos, las localidades, las regiones y territorios.

Si bien, como dice este libro, "La amplitud de los desafíos relatados, evidencia que esta es una gran tarea política. Nunca en nuestro país ha tenido lugar un proceso de esta magnitud y significado. Es una gran ocasión para poner a prueba toda la capacidad política del movimiento popular chileno (...). Es cierto que los grandes procesos de transformación social no pasan solamente por cambiar el aparato jurídico de un país. Sin embargo, sin ese cambio, tampoco son realmente posibles. (...) La Asamblea Constituyente es solo un camino. Pero puede ser un camino que nos ponga de 
nuevo en la ruta de nuestra liberación” (p.104). En ese sentido, si bien no se resolverán todos los males que aquejan nuestra sociedad, al menos se abrirán las alamedas para construir un nuevo orden social: democrático, libre e igualitario, donde la soberanía económica, política, social, cultural y ambiental no siga siendo una entelequia. 